\title{
VI. Experimental proof of Van't Hoff's constant, of Arrhenius's generalization, and of Ostwald's law of dilution in very dilute solutions
}

\section{Dr. Meyer Wildermann}

To cite this article: Dr. Meyer Wildermann (1895) VI. Experimental proof of Van't Hoff's constant, of Arrhenius's generalization, and of Ostwald's law of dilution in very dilute solutions, Philosophical Magazine Series 5, 40:242, 119-144, DOI: $10.1080 / 14786449508620713$

To link to this article: http://dx.doi.org/10.1080/14786449508620713

曲 Published online: 08 May 2009.

Submit your article to this journal

Ш Article views: 2

View related articles $\longleftarrow$ 
of experiment. These and many other points are receiving consideration, and will be discussed in a subsequent communication. We must, in conclusion, express our great obligations to Mr. D. K. Morris, as well as to Mr. C. Jakeman, for the valuable assistance they have rendered to us in the laborious work of taking and reducing the observations above recorded, as well as in the construction of some of the apparatus used in this research.

VI. Experimental Proof of Van't Hoff's Constant, of Arrhenius's Generalization, and of Ostwald's Law of Dilution in very Dilute Solutions. By Dr. Meyer WiIDERMANN *.

\section{Proof of Van't Hoff's Constant.}

TT is well known that it was Van't Hoff who first drew 1 attention to the fact that the equations representing the generalizations arrived at by Boyle, Gay-Lussac, and Avogadro in the case of gases are equally applicable to dissolved substances, if the osmotic pressure of the molecules of the dissolved substance be substituted for the pressure of the gas.

Van't Hoff deduced these laws for solution from thermodynamical considerations-a method which gives them increased validity,-and illustrated them from the osmotic experiments of Pfeffer and de Vries.

At the same time Van't Hoff was able to establish a thermodynamical relation between the osmotic pressure of a dissolved substance and the molecular lowering of vapour-pressure; molecular lowering of freezing-point of the solution thereby furnishing a rational basis for the empirical generalizations of Raoult and of Babo and Wüllner, who had previously investigated the same point.

In Van't Hoff's thermodynamical argument the solutions are assumed to be very dilute, and hence their experimental verification is specially important for the case of very dilute solutions.

The determination of the molecular depression of the freezing-point is the safest and most convenient method of testing the validity of these generalizations, and this has been done for moderately dilute solutions by Van't Hoff himself

* Conmunicated by the Author: read before the British Association on the 13th of August, 1894. 
and by Ejkman ; and the equation

$$
t=\frac{0.02 \mathrm{~T}^{2}}{w}
$$

where $\mathrm{T}=$ absolute temperature, $w=$ latent heat of fusion of the solvent, has been experimentally verified and confirmed for several solvents.

The method of determining the freezing-point of very dilute solutions*, which was devised by my late friend P. B. Lewis, from $0^{\circ}$ to $-0^{\circ} \cdot 2$, and $m y$ recent investigations of similar solutions from $-0^{\circ} \cdot 2$ to $-0^{\circ} \cdot 4$ and of the freezingpoint of water $\dagger$, have given us a means of submitting Van't Hoff's equation,

$$
t=\frac{0.02 \mathrm{~T}^{2}}{w}
$$

to a more accurate verification.

'The value of $t$ is 1.87 if, with Bunsen and others, we take the latent heat of water to be $80 \mathrm{cal}$,, and is somewhat greater if $w$ is put $=79.6 \mathrm{cal}$.

First come the experimental data. In the following Tables $\alpha$ is the number of molecules in solution per litre (in pure water this is 0$) ; \gamma$ is the freezing-point of the water or of the solution, as read on the ${ }_{10}^{1} \overline{0}^{\circ}$ thermometer; $\delta$ the number of readings of the temperature made after the freezing-point has been reached; $\epsilon$ the limits within which the readings of the temperature varied; $\phi$ is the time over which the readings extended ; $b$ is the amount of over-cooling, or difference between the temperature of the solution before and after the formation of ice, these temperatures being read on the $\frac{1}{10}{ }^{\circ}$ thermometer; $c$, the temperature of the ice-batb; $c^{\prime}$, the temperature of the room; $k$ is the reading of the barometer.

* See 'Transactions of the Chemical Society,' 1894. A fuller account bas been given in the Zeitschrift fuir phys. Chemie, xv. p. 358. See also the very valuable work of Jones, Zeitschr. phys. Chemie, xi. p. 110. Later' investigations of Jones have shown that his method was not brought to the high development we all supposed. It is now a long time ago since Professor Ostwald told me that it is also his opinion that the method used by Jones requires a further development, because the results obtained for non-electrolytes by this method do not agree with the fundamental generalizations of the modern Theory of Solutions. The work of Lewis, which is distinguished by great experimental accuracy, and by the minute and judicions care with which the conditions necessary to secure the best possible results are investigated, enables us now to submit many important questions in very dilute solutions to a more accurate verification.

$\dagger$ See Zeitschr. phys. Chemie, xv. p. 365. 
TABle I. (1/1000 thermometer.)

\begin{tabular}{|c|c|c|c|c|c|c|c|c|}
\hline \multicolumn{9}{|c|}{ Cane-sugar. } \\
\hline$\alpha$. & $\gamma$ & $\delta$ & $\epsilon$. & $\phi$. & $b$. & $c$. & $c^{\prime}$. & $k$. \\
\hline $\begin{array}{l}0^{*} \\
0 * \\
0 \dagger \\
0 \cdot 006535 \ddagger \\
0.019344 \ddagger \\
0.03164 \ddagger \\
0.04344 \ddagger\end{array}$ & $\begin{array}{l}-4858(9) \\
\cdot 4857(8) \\
\cdot 4873(4) \\
4758(7) \\
\cdot 4514(3) \\
\cdot 4279(8) \\
\cdot 4067(6)\end{array}$ & $\begin{array}{l}5 \\
4 \\
7 \\
7\end{array}$ & $\begin{array}{r}\cdot 4858-4859 \\
\cdot 4857-4858 \\
\ldots \ldots \\
\cdot 4758-4757 \\
\cdot 4514-4513 \\
\cdot 4279-4277 \\
\cdot 4066-4068\end{array}$ & $\begin{array}{r}3 \\
8 \\
10 \\
10\end{array}$ & & $\begin{array}{l}-1.8 \text { to }-.8 \\
-1.8 \text { to }-2 \\
\ldots \ldots \\
-1.8 \text { to }-2 \\
-1.8 \text { to }-2 \\
-2 \\
-2\end{array}$ & $\begin{array}{l}18 \\
18 \\
\ldots \\
18 \\
18 \\
18 \cdot 2 \\
18 \cdot 3\end{array}$ & $\begin{array}{c}\text { millim. } \\
756 \cdot 5 \\
756 \cdot 3 \\
756 \cdot 3 \\
756 \cdot 5 \\
757 \cdot 5 \\
757 \cdot 5 \\
757 \cdot 5\end{array}$ \\
\hline $\begin{array}{l}0.05477 \ddagger \\
0.06565 \ddagger \\
0.07609 \\
0 \cdot 08612\end{array}$ & $\begin{array}{l}.3848(9) \\
.3634 \\
.3428(9) \\
.3233(4)\end{array}$ & $\begin{array}{l}7 \\
9 \\
6 \\
6\end{array}$ & $\begin{array}{l}\cdot 3847-3849 \\
-3633-3635 \\
-3427-3429 \\
\cdot 3233-\cdot 3234\end{array}$ & $\begin{array}{l}10 \\
10 \\
10 \\
10\end{array}$ & & $\begin{array}{l}-2 \\
-2 \\
-2 \\
-2\end{array}$ & $\begin{array}{l}17 \cdot 5 \\
17 \cdot 3 \\
17 \cdot 1 \\
17\end{array}$ & $\begin{array}{l}760 \cdot 5 \\
760 \cdot 5 \\
760 \cdot 5 \\
760 \cdot 5\end{array}$ \\
\hline \multicolumn{9}{|c|}{ Urea. } \\
\hline $\begin{array}{l}0 * \\
0 * \\
0 † \\
0001813 \ddagger \\
000905 \ddagger \\
0002341 \ddagger\end{array}$ & $\begin{array}{l}4851(2) \\
4852 \\
4867(8) \\
4819 \\
46994 \\
-4427(8)\end{array}$ & $\begin{array}{l}8 \\
7 \\
7 \\
7 \\
5 \\
6\end{array}$ & $\begin{array}{r}-4850-\cdot 4852 \\
\cdot 4852-\cdot 4853 \\
\cdot \ldots \ldots \\
\cdot 4819-4820 \\
\cdot 4694-4692 \\
\cdot 4628-\cdot 4628\end{array}$ & $\begin{array}{l}8 \\
5 \\
9\end{array}$ & & $\begin{array}{l}-1.7 \\
-1.8 \text { to }-2 \\
\ldots \ldots . \\
-1.8 \\
-2 \\
-1.8\end{array}$ & $\begin{array}{l}20 \\
19 \\
73 \\
18 \\
18 \cdot 5 \\
18 \cdot 5\end{array}$ & $\begin{array}{l}760 \cdot 65 \\
760 \cdot 5 \\
760 \cdot 5 \\
760 \cdot 5 \\
760 \cdot 4 \\
760 \cdot 5\end{array}$ \\
\hline $\begin{array}{l}0 * \\
0 \cdot 043506 \pm \\
0.07802 \ddagger \\
0.11116 \ddagger\end{array}$ & $\begin{array}{l}4852(3) \\
-4026(7) \\
-3355(6) \\
.2687(8)\end{array}$ & $\begin{array}{l}6 \\
6 \\
6 \\
8\end{array}$ & $\begin{array}{l}\cdot 4851-\cdot 4853 \\
\cdot 4026-4027 \\
\cdot 3355-3358 \\
\cdot 2685-2688\end{array}$ & $\begin{array}{r}12 \\
9 \\
7 \\
12\end{array}$ & & $\begin{array}{l}-2 \\
-1 \cdot 8 \\
-1 \cdot 8 \\
-2\end{array}$ & $\begin{array}{l}19 \cdot 7 \\
19 \cdot 3 \\
19 \cdot 1 \\
19\end{array}$ & $\begin{array}{l}759 \cdot 5 \\
759 \cdot 5 \\
759 \cdot 5 \\
759 \cdot 5\end{array}$ \\
\hline \multicolumn{9}{|c|}{ Alcohol, $\mathrm{C}_{2} \mathrm{H}_{5} \mathrm{OH}$. } \\
\hline $\begin{array}{l}0 * \\
0 \dagger \\
0.00645 \ddagger \\
0.01930 \ddagger \\
0.04495 \ddagger \\
0.09582 \ddagger \\
0.1459 \ddagger\end{array}$ & $\begin{array}{l}-4844(5) \\
-4860(1) \\
-4738 \\
-4510(1) \\
-4033 \\
-3086 \\
-2152\end{array}$ & $\begin{array}{l}7 \\
5 \\
9 \\
9 \\
6\end{array}$ & $\begin{array}{r}\cdot 4845-\cdot 4854 \\
. \ldots . \\
\cdot 4737-\cdot 4739 \\
\cdot 4510-\cdot 4512 \\
\cdot 4032-4034 \\
\cdot 3085-3087 \\
\cdot 2152-\cdot 2151\end{array}$ & $\begin{array}{r}10 \\
\dddot{8} \\
8 \\
12 \\
12 \\
10\end{array}$ & & $\begin{array}{l}-1 \cdot 8 \\
-1.8 . \\
-2 \\
-2 \\
-2 \\
-2\end{array}$ & $\begin{array}{l}15 \cdot 6 \\
\ldots \\
15 \\
14 \\
13 \cdot 8 \\
13 \cdot 5 \\
13 \cdot 5\end{array}$ & $\begin{array}{l}754 \cdot 2 \\
754 \cdot 2 \\
754 \cdot 2 \\
754 \cdot 5 \\
754 \cdot 8 \\
754 \cdot 8 \\
754 \cdot 8\end{array}$ \\
\hline $\begin{array}{l}0 * \\
0.1548 \ddagger \\
0.2039 \ddagger \\
0.2039 \ddagger\end{array}$ & $\begin{array}{l}-4848(7) \\
-1985 \\
-1064 \\
1068(4)\end{array}$ & $\begin{array}{l}6 \\
9 \\
6 \\
6\end{array}$ & $\begin{array}{l}\cdot 4848-\cdot 4847 \\
\cdot 1984-1986 \\
\cdot 1063-\cdot 1065 \\
\cdot 1063-\cdot 1064\end{array}$ & $\begin{array}{r}10 \\
10 \\
12 \\
9\end{array}$ & & $\begin{array}{l}-1.8 \text { to }-2 \\
-2 \\
-1.8 \text { to }-2 \\
-2\end{array}$ & $\begin{array}{l}15 \cdot 5 \\
15 \cdot 5 \\
15 \cdot 3 \\
15 \cdot 2\end{array}$ & $\begin{array}{l}753 \cdot 7 \\
7537 \\
753 \cdot 6 \\
753 \cdot 7\end{array}$ \\
\hline
\end{tabular}

* Ice-cay on the bulb of the thermometer.

+ Ditto, corrected by $+0^{0} 0016$.

$\ddagger$ No ice-cap is formed on the $\mathrm{Hg}$ bulb of the thermometer. 
From these experimental data are deduced the following Tables, in which are given :-

$\alpha$, the number of molecules of the substance dissolved, p.litre. $a$, the lowering of the freezing-point which is observed.

$b$, the number of degrees of over-cooling read on the smaller thermometer.

$c$, the amount of the solvent which separated as ice, expressed in percentages.

$d$, the factor by which the number of molecules given under $\alpha$ must be multiplied in order to obtain

a corrected; $i . e$. the concentration of the solution after the separation of the ice. (It is better to correct the density than the lowering of the freezing-point, on account of dissociation.)

$\frac{a}{a \text { corrected }}$ gives the molecular lowering of the freezingpoint, which, according to Van't Hoff, is represented by

$$
\begin{aligned}
t=\frac{0 \cdot 02 \mathrm{~T}^{2}}{w} & =1.878(\text { if } w=79 \cdot 6) \\
& =1.87 \quad(\text { if } w=80) .
\end{aligned}
$$

or

\begin{tabular}{|c|c|c|c|c|c|c|}
\hline \multicolumn{7}{|c|}{ Cane-sugar. } \\
\hline a mol. norm. & a. & $b$. & e. & $d$ & $a$ corr. & $\beta=\frac{a}{a \text { corr. }} \times 100$ \\
\hline (1.) & {$\left[\begin{array}{c}0.0100(1)] \\
0.016(7)\end{array}\right.$} & 0.888 & $\begin{array}{c}\text { per cent. } \\
1.06\end{array}$ & $\frac{100}{98.94}$ & $0 \cdot 006602$ & $\begin{array}{c}{[151 \cdot 5]} \\
175 \cdot \%(1 \% 7 \cdot \mathscr{2})\end{array}$ \\
\hline$\stackrel{(2 .)}{0.019344}$ & {$\left[\begin{array}{c}0.0344(5)] \\
0.0360(1)\end{array}\right]$} & 0.855 & 1.03 & $\frac{100}{98 \cdot 97}$ & 0.019546 & $\begin{array}{l}{[176(176 \cdot 5)]} \\
184.5(184 \%)\end{array}$ \\
\hline$\stackrel{(3 .)}{0 \cdot 03164}$ & {$\left[\begin{array}{c}0.0579(80)] \\
0.0595(6)\end{array}\right.$} & 0.731 & 0.88 & $\frac{100}{99 \cdot 12}$ & 0.03192 & $\begin{array}{l}{[181 \cdot 4(181 \cdot 7)]} \\
\left.186 \cdot 4\left(186^{\circ} \cdot 7\right)\right]\end{array}$ \\
\hline (4.) 0.04344 & {$\left[\begin{array}{c}{[0.0792(1)]} \\
0.0808(9)\end{array}\right.$} & $0 \cdot 789$ & 0.95 & $\frac{100}{99 \cdot 05}$ & 0.04386 & $\begin{array}{l}{[180 \cdot 6(180 \cdot 3)]} \\
184^{\circ} \cdot(184 \cdot 5)\end{array}$ \\
\hline (5.) & {$\left[\begin{array}{c}{[0 \cdot 1010(1)]} \\
0 \cdot 1026(7)\end{array}\right.$} & 0.755 & 0.91 & $\frac{100}{99 \cdot 09}$ & 005527 & $\begin{array}{c}{[182 \cdot 7(122.9)]} \\
185 \cdot 6(185 \cdot 8)\end{array}$ \\
\hline (6.) & {$\left[\begin{array}{c}0 \cdot 1224] \\
0 \cdot 1240(1)\end{array}\right.$} & 0.673 & 0.81 & $\frac{100}{9 y \cdot 19}$ & 0.06619 & $\frac{[184 \cdot 9]}{18 \% \cdot 3(187 \cdot 5)}$ \\
\hline${ }^{(7 .)}{ }_{0.07609}$ & $\begin{array}{c}0 \cdot 1430(1)] \\
0 \cdot 1446(7 \cdot 8)\end{array}$ & 0.751 & 0.90 & $\frac{100}{99 \cdot 1}$ & 0.07678 & {$\left[\begin{array}{c}186 \cdot 2(186 \cdot 4)] \\
188.3(188.5)\end{array}\right.$} \\
\hline$\stackrel{(8 .)}{0.08612}$ & {$\left[\begin{array}{c}{[0 \cdot 1624(5)]} \\
0.1640(1 j)\end{array}\right.$} & 0.643 & 0.77 & $\frac{100}{99 \cdot 25}$ & 0.08679 & {$\left[\begin{array}{c}187 \cdot 1(187 \cdot 3)) \\
189 \cdot 0(189 \cdot 1)\end{array}\right.$} \\
\hline
\end{tabular}

TABLE II. 
Urea.

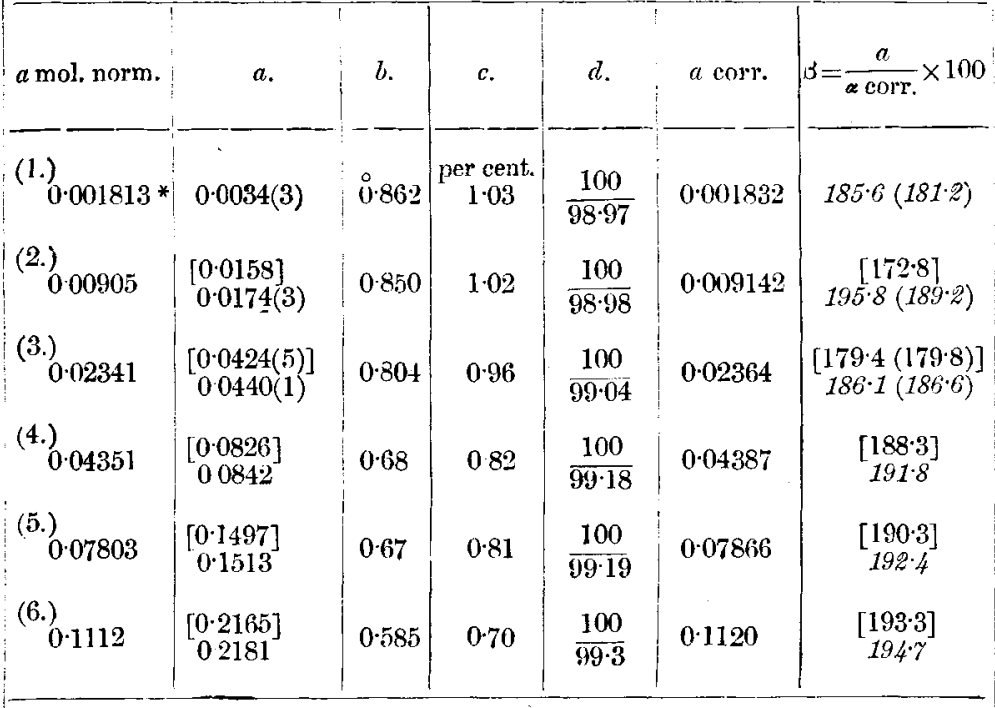

Alcohol, $\mathrm{C}_{2} \mathrm{H}_{5} \mathrm{OH}$.

\begin{tabular}{|c|c|c|c|c|c|c|}
\hline (1.) 0.00645 & $\begin{array}{c}{[00106(7)]} \\
00122(3)\end{array}$ & 0.94 & $\underset{1}{\operatorname{per} \text { cent. }} \mathbf{1 8}$ & $\frac{100}{9882}$ & 0.006527 & $\begin{array}{c}{\left[\begin{array}{l}162.4 \\
186.9\end{array}(168.9)\right]} \\
(188.4)\end{array}$ \\
\hline (2.) 0.01930 & {$\left[\begin{array}{c}0.0337 \\
0.0353\end{array}\right]$} & 0.975 & $1 \cdot 22$ & $\frac{100}{98 \cdot 78}$ & 0.01953 & 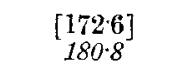 \\
\hline${ }^{(3 .)} 0.04495$ & {$\left[\begin{array}{c}0.0811(2)] \\
0.0827(8)\end{array}\right.$} & 0.933 & $1 \cdot 166$ & $\frac{100}{9883}$ & 0.04548 & 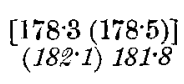 \\
\hline (4.) 0.09582 & $\begin{array}{c}{[0.1758(9)]} \\
0.1774(5)\end{array}$ & 0.87 & $1 \cdot 09$ & $\frac{100}{98.91}$ & 0.09688 & {$\left[\begin{array}{c}181 \cdot 5(181 \cdot 6)] \\
(183 \cdot 8) 183 \cdot 1\end{array}\right.$} \\
\hline (5.) 0.1459 & {$\left[\begin{array}{l}0.2692(3)] \\
027(08(9)\end{array}\right.$} & 0.739 & 092 & $\frac{100}{9908}$ & 0.1472 & $\begin{array}{c}{[182 \cdot 9(183)]} \\
184\end{array}$ \\
\hline (6.) 0.1548 & $\begin{array}{c}{[0.2862(3)]} \\
0.2878(9)\end{array}$ & $0 \cdot 70$ & $0 \cdot 88$ & $\frac{100}{99 \cdot 12}$ & $0 \cdot 1562$ & $\begin{array}{c}{\left[\begin{array}{l}183 \cdot 2 \\
184.3\end{array}\right]} \\
\end{array}$ \\
\hline (7.) 0.2039 & $\begin{array}{c}{[0.3783(4)]} \\
0.3799(800)\end{array}$ & 062 & $0 \cdot 785$ & $\frac{100}{99 \cdot 22}$ & $0 \cdot 2055$ & {$\left[\begin{array}{l}184 \cdot 1] \\
1849\end{array}\right.$} \\
\hline$\left(7^{\prime} .\right)_{0.2039}$ & $\begin{array}{c}{[0.3784]} \\
0.3800\end{array}$ & 0665 & 0.83 & $\frac{100}{99 \cdot 17}$ & 02056 & $\frac{[184 \cdot 1]}{18 \cdot 9 \cdot 9}$ \\
\hline
\end{tabular}

* Ice-cap on the bulb of the thermometer. 
In the above tables under $a$ and $\beta$ two values are given. In the case of cane-sugar, alcohol, and urea (with the exception of the solution of urea which contains 0.001813 molecules per litre) there were, with all concentrations, fine needles of ice in the solution, but no ice-cap on the thermometer. In square brackets there are given under $a$ and $\beta$ the values which have been obtained when the freezing-point of water, as read off when there was a well-closed ice-cap round the bulb of the big (and the little) thermometer, is taken as the true zero ; the other figures (without brackets) under $a$ and $\beta$ are obtained when the freezing-point of water, as read off when there is no ice-cap round the bulb, is taken as the true zero.

In the latter case (of a well-closed ice-cap) the freezingpoint of water has been found to be under my experimental conditions on an average $0^{\circ} .0016$ higher $*$, and may err, like all determinations in very dilute solntions, by about 1, 2, or less often 3 ten-thousandths of a degree. In the above tables the figures and results are given exactly as they were obtained from the observations. In these tables, in the cases of canesugar and urea, Van't Hoff's constant appears very clearly if the completely closed ice-cap be avoided in the determination of the freezing-point of water, and would appear still more clearly if one were to make the allowable correction of from 1 to 2 or 3 ten-thousandths of a degree : in short, so far as the degree of exactitude of the method itself allows, Van't Hoff's constant appears very clearly. In the cases of alcohol and cane-sugar the values of $\beta$ fall in the more dilate solutions short of 1.87 by about $1 \frac{1}{2}$ per cent.

The importance of the question on which we are engaged induces me to point out that Van't Hoff's constant can also be demonstrated most distinctly, independently of the freezingpoint of water. Since cane-sugar, urea, and alcohol can only be very little dissociated, we can determine the several depressions and concentrations, starting from a given solution which does not cause the formation of an ice-cap round the bulb of the thermometer (instead of taking water as the starting-point), and state the results in relation to this ; by this means any error which attaches to the determination of the freezing-point of water is eliminated. Starting, then, from the most dilute solution, in which no ice-cap was observed, the following results are obtained :-

* The convergence temperature was here above the freezing-point temperature. 
Proof of Van't Hoft's Constant.

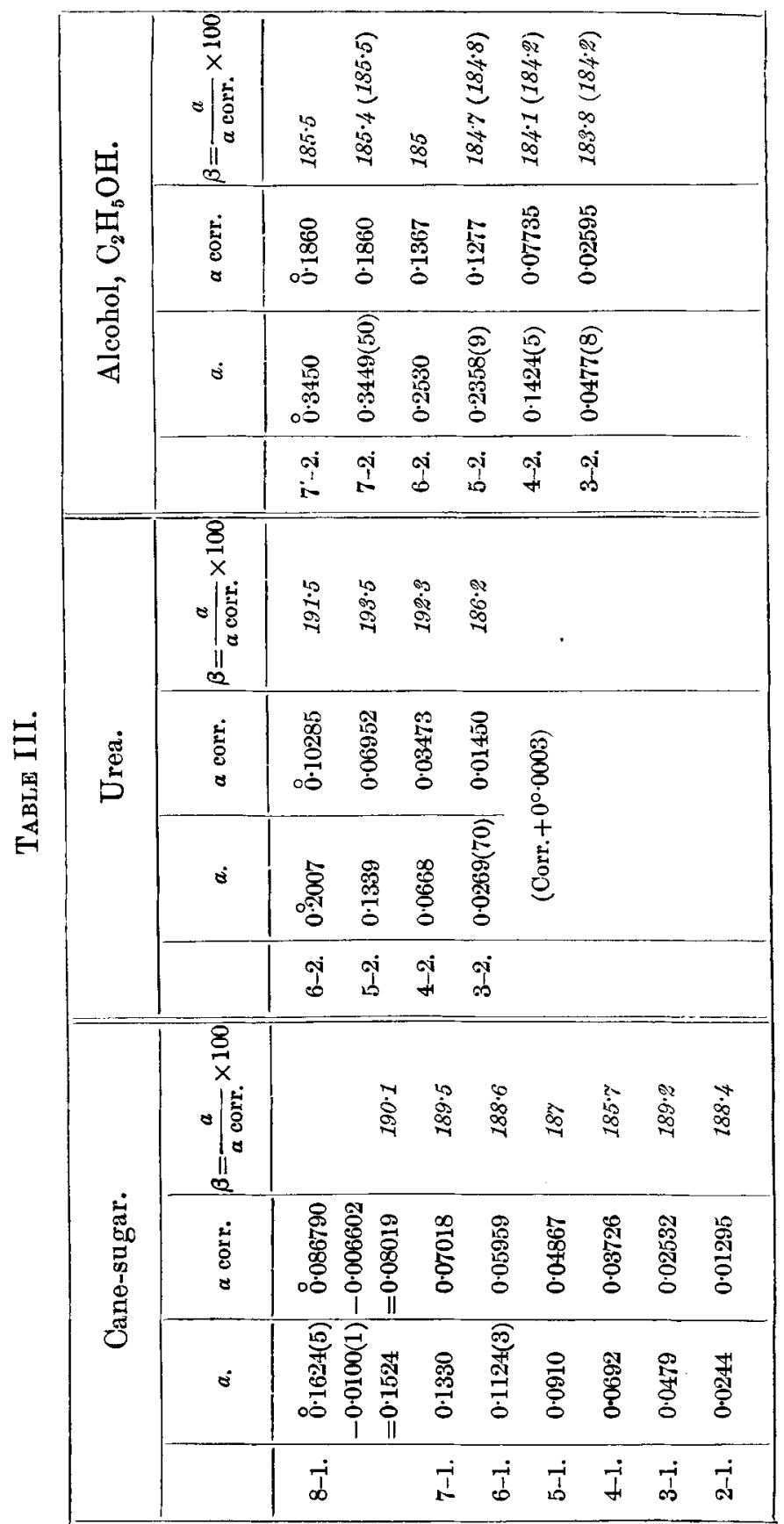


Thus, by this plan, the constant 1.87 or 1.88 appears very satisfactorily in the case of sugar and urea, and in the case of alcohol the constant is only about $1 \frac{1}{2}$ per cent. too small. The general run of the values of $\beta$ in the cases of cane-sugar, urea, and alcohol, shows that in the more concentrated solutions the values obtained for the molecular lowering of the freezingpoint are greater than 1.87 , and that it is only as the solutions become more dilute that the constant 1.87 becomes apparent. Now Van't Hoff's laws were only deduced for very dilute solutions, for "ideal" solutions.

This year I repeated the investigations of cane-sugar, alcohol, \&c. under more favourable conditions, where no closed ice-cap but ice-bands or network of ice are formed round the $\mathrm{Hg}$ bulb of the ${ }_{\mathrm{T} 0 \mathrm{o}}^{\mathrm{l}}{ }^{\circ}$ thermometer, and the convergence temperature was under the freezing-point temperature. The difference in the capsules is conditioned by the differing of the ice-crystal, which is brought into the over-cold liquid to crystallize it. When the convergence temperature is under the freezing-temperature, the correct freezing-point of water, as well as of solutions, is directly obtained with the ice-cap. [A consideration of the processes which take place at the freezingtemperature, when the convergence temperature is above and under the freezing-temperature, is of great interest and will form the subject of a separate communication.] Thus I have shown by this third method, that Van't Hoff's constant holds good in dilute solutions. Table $\mathrm{I}^{\prime}$. gives the experimental data obtained with the $\frac{1}{1000}{ }^{\circ}$ and $\frac{1}{100}{ }^{\circ}$ thermometer for canesugar, alcohol, and from these data table $\mathrm{II}^{\prime}$. is deduced. 'The Van't Hoff constant appears very clearly, and is in the most dilute solution only about $1 \frac{1}{2}$ per cent. less than 1.87 . Table III'. gives the molecular depressions, starting from the most dilute solutions, for cane-sugar \&c.

'TABLE III'.

\begin{tabular}{|c|c|c|c|c|c|}
\hline & \multirow{2}{*}{ \& corr. } & \multicolumn{2}{|c|}{$1 / 1000^{\circ}$ Thermometer. } & \multicolumn{2}{|c|}{$1 / 100^{\circ}$ Thermometer. } \\
\hline & & $a$. & $\beta$. & $a$. & $\beta$. \\
\hline $2-1$. & $0 \cdot 003985$ & 0.0073 & $183 \cdot 2$ & 00069 & $173 \cdot 1$ \\
\hline $3-1$. & $0 \cdot 011687$ & 0.0221 & $189 \cdot 1$ & 00218 & $\begin{array}{c}140.1) \\
186.5\end{array}$ \\
\hline $4-1$. & $0 \cdot 018727$ & 0.0346 & 184.7 & 00339 & 181 \\
\hline $5-1$ & $0 \cdot 028437$ & $0 \cdot 0521$ & $183 \cdot 2$ & 0.0519 & $\begin{array}{c}182.5 \\
\& c .\end{array}$ \\
\hline
\end{tabular}




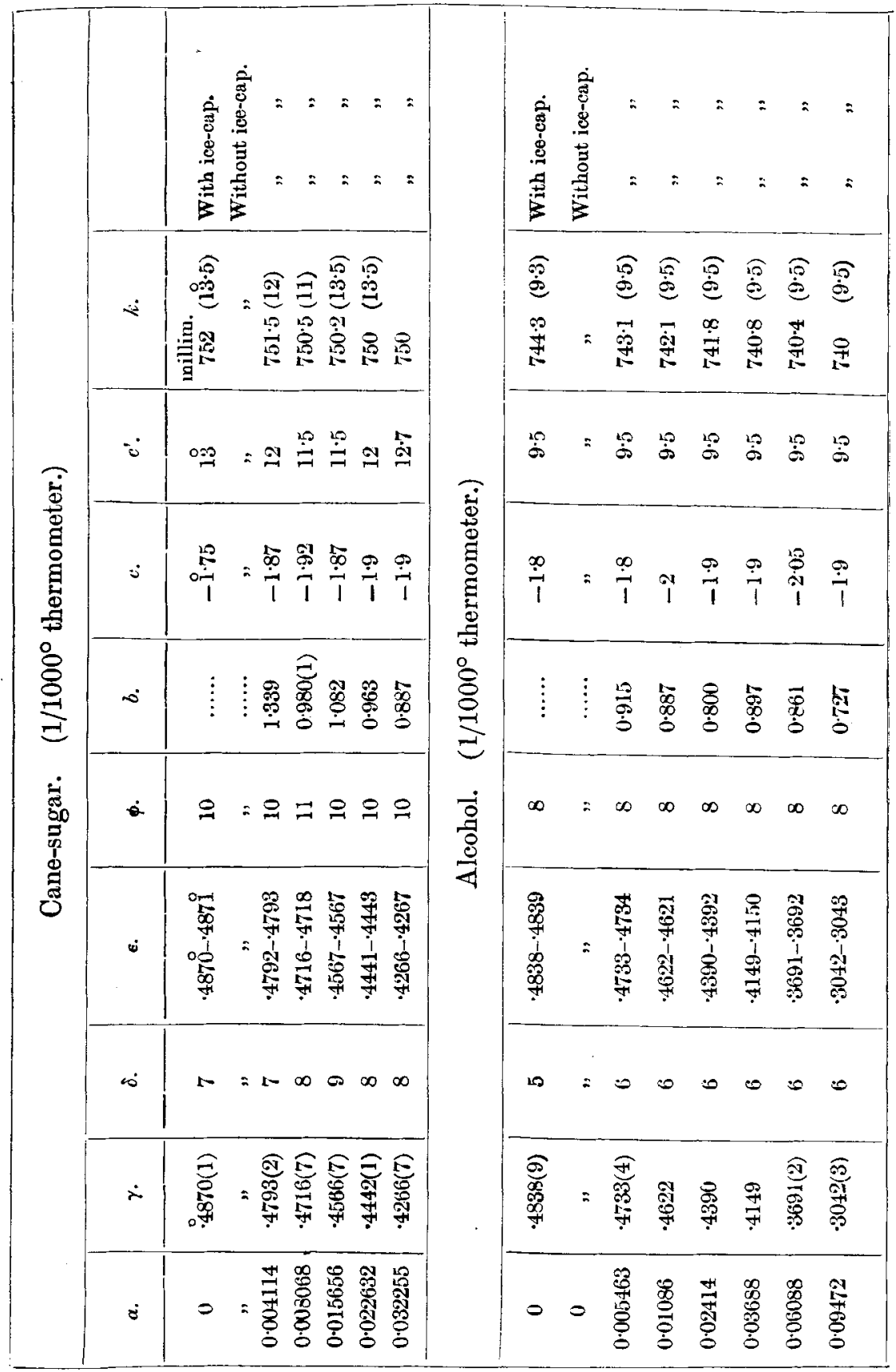




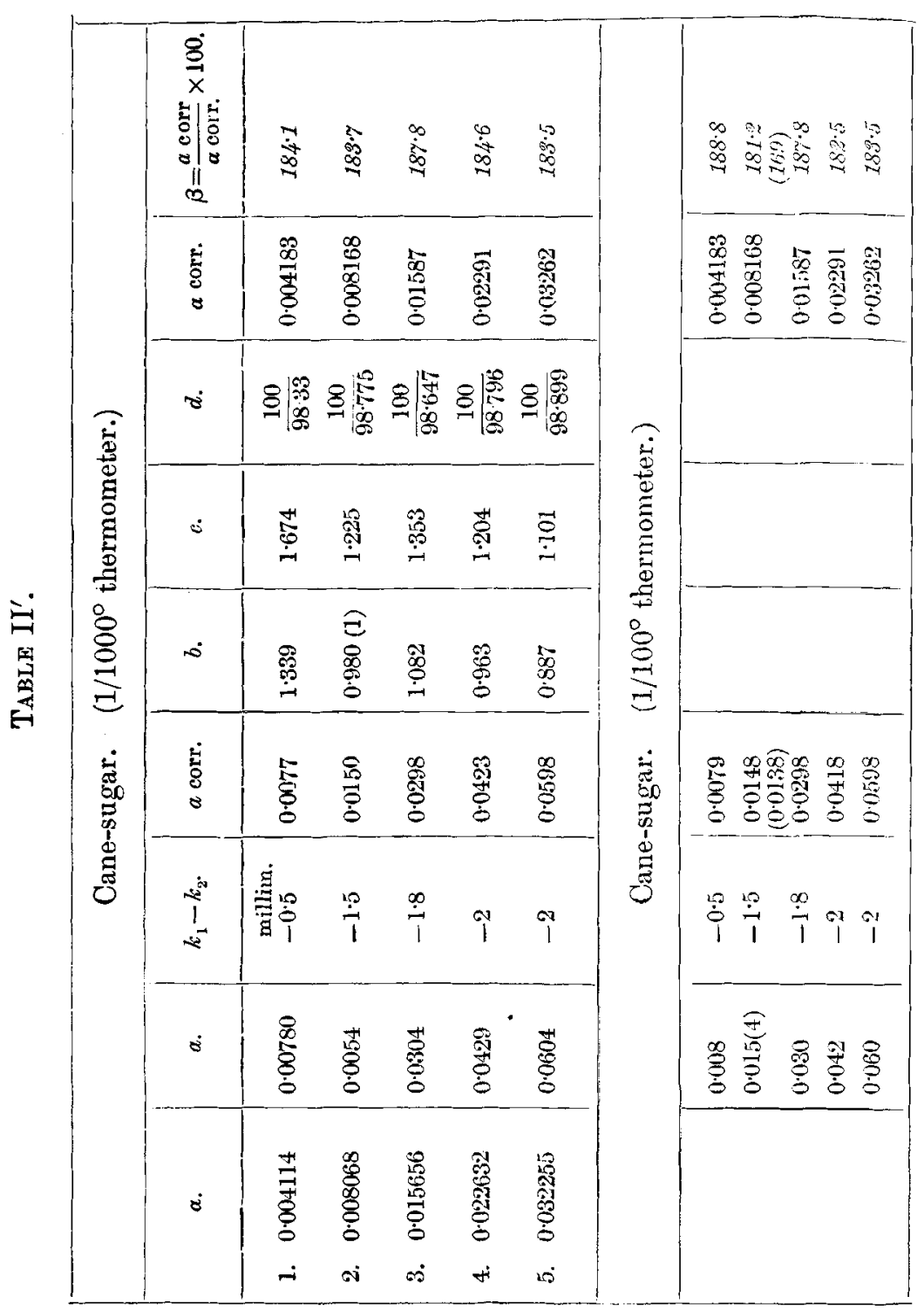


Proof of Van't Hoff's Constant.

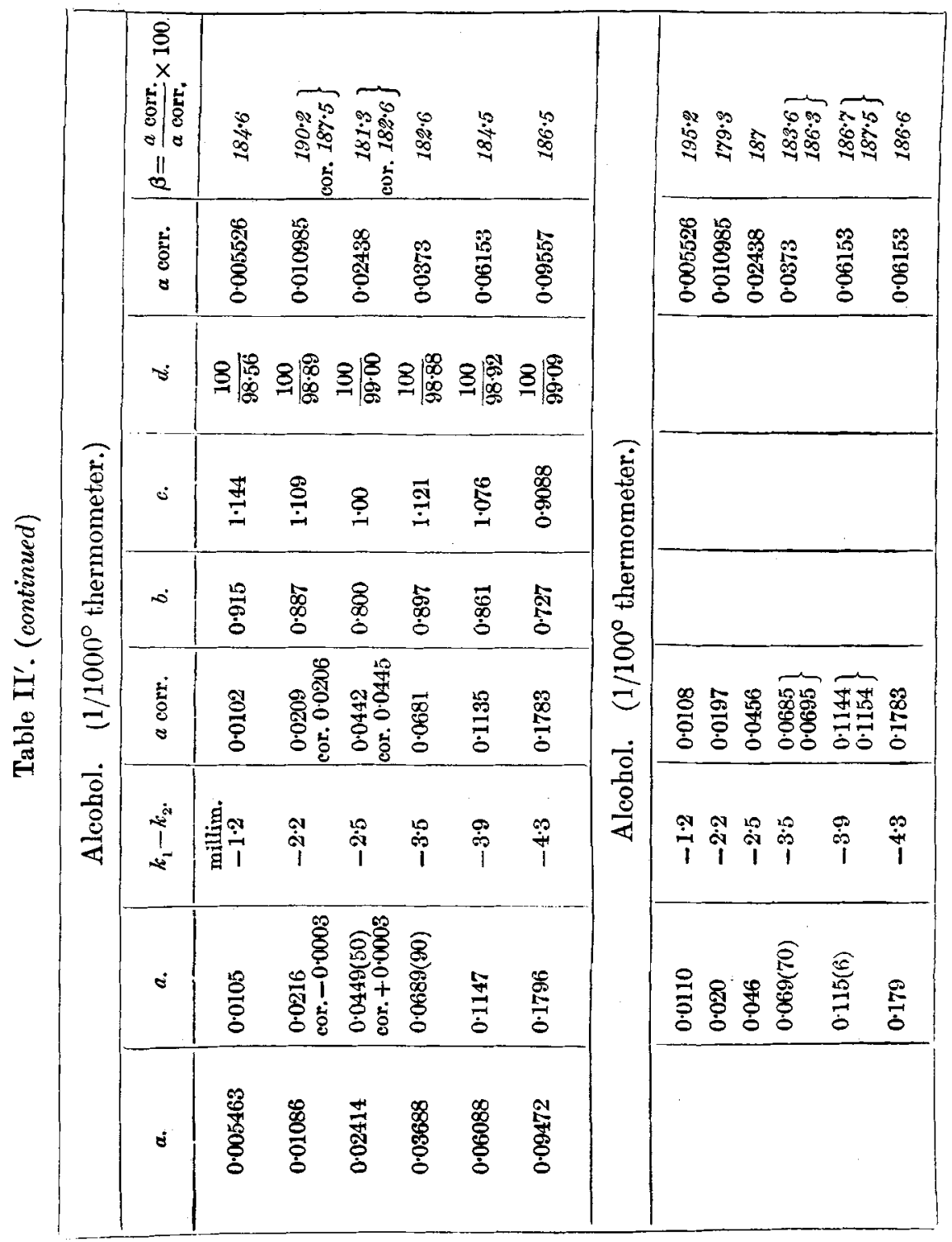

Phil, Mag. S. 5. Vol, 40. No. 242. July 1895. K 
In any case, what has still to be said is, that there are present subsidiary causes which might in part affect the equation and the constant 1.87 : such as dilution-heat put forward by Van't Hoff himself, by Nernst, and recently by Dieterici and by Evans; or as the formation of higher molecules, which I believe to be present in greater or lesser number in all solutions. But the influence of such causes could only be slight, and the only relations here quite certainly expressed are those given by Van't Hoff in the equation $t=\frac{0.02 . T^{2}}{w}$. Besides this I regard it for various reasons as very probable that the absolute value of the scale of my thermometer is, between $0^{\circ} \cdot 4900$ and $0^{\circ} \cdot 3900$ or $0^{\circ} 3600$, 1-2 per cent. too small. My further investigations will decide this question. In every case Van't Hoff's thermodynamical equation has found excellent confirmation in dilute solutions, much better even than most generalizations established on the thermodynamical basis.

The results of Loomis (Wied. Ann. li.) obtained with the $\tau_{100}^{\circ}$ thermometer, which show a continuous decrease of the values of $\beta$, may now be calculated, starting from the most dilute solutions ( $\frac{1}{10}$ mol. normal) (Table IV.).

The observations of Loomis (made with a $\frac{1}{100}{ }^{\circ}$ thermometer) extend to $\frac{1}{100}$ molecule-normal. The lowering of the freezing-point for a $\frac{1}{100}$ molecule-normal solution of a "non-conductor" is about $0^{\circ} .0187$; with such a fall of the freezing-point no formation of an ice-cap round the bulb of the thermometer is possible. Here we have taken the $1 \frac{1}{100}$ molecule-normal solution as starting-point, and the result is that Loomis's investigations point indubitably to Van't Hoff's constant. In the case of cane-sugar the figure obtained with almost all the more dilute solutions is 187 ; in the case of ureat and alcohol we obtain constants which are too small by 2 or 3 per cent. But the fact that these constants are almost the same at all concentrations shows most clearly that Mr. Loomis has not correctly determined the strength of his original solutions-a mistake which does not depend on the method itself: The low values of the molecular lowering of the freezing-point obtained by Loomis, values which for a $\frac{1}{100}$ normal solution are already too small by 10 and more per cent., may be therefore here attributed in the first place to incorrect determination of the freezing-point of water. But the not unimportant fluctuations in the value of $b$ in the cases of alcohol and urea (after the elimination of the error which may depend on the freezing-point of water), which will be noticed in the above tables, shows this, that results obtained with a $\frac{1}{100}{ }^{\circ}$ thermometer, in spite of the exactitude which 
Proof of Van't Hoff's Constant. 131

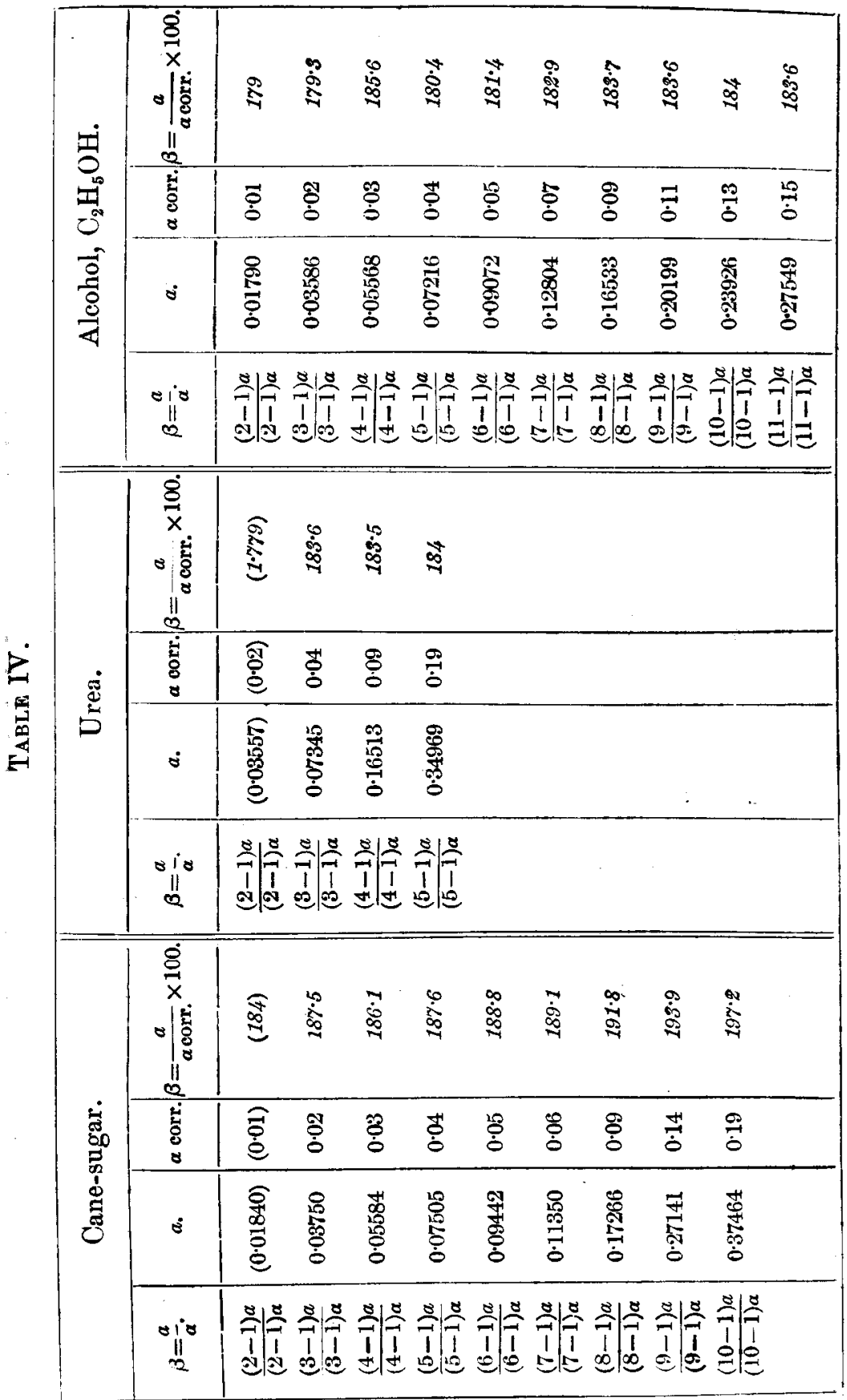


distinguishes Loomis's method in a great many points, are affected with greater experimental errors than Mr. Loomis supposes to be possible. The results which I have obtained with my $\frac{1}{10} 0^{\circ}$ thermometer by a method which by far surpasses Loomis's method in precision, are more or less of the same character (see Table $\mathrm{II}^{\prime}$.). At the same time with the observations recorded above and made with a $\frac{1}{1000} 0^{\circ}$ thermometer on cane-sugar, urea, and alcohol, similar observations were made with a $\frac{1}{10.0}$ thermometer. The results obtained are affected by experimental errors of from $0^{\circ} .001-0^{\circ} .002^{\circ}$, and even occasionally greater; and that means that we cannot use the $\frac{1}{100}^{\circ}$ thermometer for minute readings in very dilute solutions. For with the $\frac{1}{100}^{\circ}$ thermometer we have to deal with experimental errors which cannot easily be removed or eliminated. In the first place it is not easy to avoid errors of from 1 to 2 thousandths degree in making the readings, even with the use of a microscope and a micrometer-scale, although with the method mentioned above we are able to observe the obtained freezing-point during the 10 to 15 minutes occupied making several readings; the more must that be the case with other methods, where the obtained freezingpoint can be observed only a short time. Now even in solutions which are only diluted to $\frac{1}{25}$ or $\frac{1}{50}$ molecule-normal, an experimental error of $0^{\circ} .002$ makes a difference of about 3 to 5 per cent. (in the case of non-conductors) in the lowering observed, and therefore also in the calculated molecular lowering of the freezing-point. The $\frac{1}{100}$ thermometer can therefore in very dilute solutions only give us qualitative data.

\section{Proof of Arrhenius's Generalization.}

We proceed to the generalization of Arrhenius. Van't Hoff' showed by four different methods, that a law analogous to that of Avogadro was valid for solutions of non-electrolytes like cane-sugar; it then became of importance to account for exceptional cases in which the depression of freezing-point was abnormal, and in particular the cases of salts, acids, and bases in aqueous solution. The explanation was given when Arrhenius showed that by two independent quite different methods, the observation of lowering of freezing-point and of the electrical conductivity of a solution, the same value would be obtained for the factor $i$, which denotes the ratio of the pressure actually exerted by the substance to the pressure which the substance would exert if it consisted entirely of undissociated molecules.

Arrhenius made determinations on about 40 bodies in moderately dilute solutions of various concentrations and verified 
the law more accurately. From the intimate connexion which exists between Van't Hoff's laws and the dissociation theory, it follows also that the generalization of Arrhenius may find a more exact experimental confirmation in dilute solutions. Therefore a more exact confirmation of the generalization of Arrhenius in very dilute solutions is not only important on account of the great light which the theory of dissociation has thrown upon the two provinces of chemistry and physics, but it is also important inasmuch as thereby the laws of Van't Hoff will find in every point their more exact confirmation.

We found above the normal value of the molecular lowering of the freezing-point in the cases of cane-sugar, urea, and alcohol-substances belonging to the class of bad conductors of electricity. In the following Tables are given the results obtained with sulphuric acid, potassium chloride, dichloracetic acid, trichloracetic acid, and orthonitrobenzoic acid. First come the experimental data. (The meanings of $\alpha, \gamma, \delta, \epsilon, \phi$, $b, c, c^{\prime}, k$, have already been given with Table I.)

TABLE V.

\begin{tabular}{|c|c|c|c|c|c|c|c|c|}
\hline \multicolumn{9}{|c|}{ Trichloracetic Acid. } \\
\hline$\alpha$ & $\boldsymbol{\gamma}$ & $\delta$ & $e$. & $\phi$ & $b$. & $c$. & $c^{\prime}$ & $k$. \\
\hline $\begin{array}{l}0^{*} \\
0 \dagger \\
0 \cdot 005132 \dagger \\
0.010182 \ddagger \\
0.017636 \ddagger \\
0 \cdot 029761 \ddagger \\
0.0414 \ddagger \\
0 * \\
0 \dagger \\
0 \cdot 04443 \ddagger\end{array}$ & $\begin{array}{l}\cdot 4842 \\
\cdot 4858(9) \\
\cdot 4666(7) \\
.4487 \\
\cdot 4232(1) \\
\cdot 3798(9) \\
.3397(8) \\
.4841 \\
.4857 \\
\cdot 3304\end{array}$ & $\begin{array}{c}7 \\
9 \\
7 \\
5 \\
6 \\
9 \\
6 \\
5 \\
\cdots \\
5\end{array}$ & $\begin{array}{l}\cdot 4842 \quad \circ \\
\cdot 4858-\cdot 4859 \\
\cdot 4666-\cdot 4367 \\
\cdot 4487 \\
\cdot 4232-\cdot 4233 \\
\cdot 3797-\cdot 3799 \\
\cdot 3397-\cdot 3399 \\
\cdot 4840-44841 \\
\ldots \ldots \\
\cdot 3304\end{array}$ & $\begin{array}{l}8 \\
10 \\
10 \\
10 \\
10 \\
12 \\
10 \\
10 \\
\ldots \\
10\end{array}$ & $\begin{array}{l}0.950 \\
0.768 \\
0.70 \\
0.978 \\
0.852 \\
0.987 \\
0.827 \\
0.748 \\
\ldots \ldots \\
0.67\end{array}$ & $\begin{array}{l}-8 \\
-2 \\
-1 \cdot 8 \\
-1 \cdot 7 \\
-2 \\
-1 \cdot 9 \\
-2 \\
-2 \\
-1 \cdot 8 \\
\ldots \ldots \\
-1 \cdot 8\end{array}$ & $\begin{array}{l}20 \cdot 3 \\
20 \cdot 6 \\
20 \\
19 \cdot 5 \\
19 \\
18 \\
18 \\
17 \cdot 5 \\
\ldots \ldots \\
17 \cdot 8\end{array}$ & $\begin{array}{l}\text { millim. } \\
758 \\
758 \\
758 \\
757 \cdot 9 \\
758 \\
758 \\
758 \\
757 \\
757 \\
757\end{array}$ \\
\hline \multicolumn{9}{|c|}{ Dichloracetic Acid. } \\
\hline $\begin{array}{l}0 * \\
0 \dagger \\
0.002573 * \\
0.005125 * \\
0.010230 \ddagger \\
0.015294 \ddagger \\
0.02032 \ddagger \\
0 * \\
0.027551 \ddagger\end{array}$ & $\begin{array}{l}-4852 \\
\cdot 4867 \\
-4758 \\
\cdot 4669(70) \\
-4515 \\
\cdot 4366(5) \\
\cdot 4220(1) \\
\cdot 4834(5) \\
\cdot 3933\end{array}$ & $\begin{array}{l}\ldots \\
\ldots \\
\ldots \\
\cdots \\
\cdots \\
\cdots \\
\cdots \\
\cdots \\
\ldots\end{array}$ & $\begin{array}{l}\ldots \ldots . . \\
\ldots \ldots . . \\
\ldots \ldots . . \\
\ldots \ldots . . \\
\ldots \ldots . \\
\ldots \ldots . . \\
\ldots \ldots . \\
\ldots \ldots . \\
\ldots \ldots .\end{array}$ & $\begin{array}{l}\ldots \\
\cdots \\
\cdots \\
\cdots \\
\cdots \\
\cdots \\
\cdots \\
\cdots \\
\cdots\end{array}$ & \begin{tabular}{l|}
0.82 \\
0.80 \\
$0 \cdot 795$ \\
0.785 \\
0.766 \\
0.730 \\
0.615 \\
0.685 \\
0.680
\end{tabular} & & & \\
\hline
\end{tabular}

* Ice-cap round the bulb of thermometer.

+ The ice-cap is avoided in a manner described in Zeitschr. phys. Chemie. Xi.

$\ddagger$ No ice-cap on the $\mathbf{H g}$ bulb of the thermometer. 
Table V. (continued).

Orthonitrobenzoic Acid.

\begin{tabular}{|c|c|c|c|c|c|c|c|c|}
\hline$\alpha$. & $\gamma$ & $\delta$. & c. & $\phi$. & $b$. & $c$ & $c^{\prime}$. & $k$. \\
\hline $\begin{array}{l}0 \dagger \\
0 \dagger \\
0 \cdot 006169 \ddagger \\
0.008318 \ddagger \\
0.01197 \ddagger \\
0.015037 \ddagger \\
0.017083 \ddagger \\
0.02046 \ddagger\end{array}$ & $\begin{array}{l}-4855 \\
\cdot 4855(6) \\
-4667 \\
\cdot 4607 \\
\cdot 4518(9) \\
\cdot 4447(6) \\
\cdot 4385(6) \\
\cdot 4308\end{array}$ & $\begin{array}{r}9 \\
5 \\
8 \\
8 \\
8 \\
8 \\
10 \\
10\end{array}$ & $\begin{array}{l}\cdot 4855-\cdot 4856 \\
\cdot 4855-44856 \\
\cdot 4866-\cdot 4867 \\
\cdot 4606-\cdot 4608 \\
\cdot 4517-\cdot 4519 \\
\cdot 4446-\cdot 4447 \\
\cdot 4385-\cdot 4387 \\
\cdot 4206-4310\end{array}$ & $\begin{array}{r}6 \\
6 \\
9 \\
10 \\
10 \\
8 \\
8 \\
7\end{array}$ & $\begin{array}{l}0 \cdot 8 \\
0 \cdot 78 \\
0 \cdot 78 \\
0 \cdot 734 \\
0 \cdot 766 \\
0 \cdot 778 \\
0 \cdot 72 \\
0 \cdot 81\end{array}$ & $\begin{array}{l}-1.8 \\
-1.8 \\
-1.8 \\
-1.8 \\
-1.8 \\
-1.8 \\
-1.8 \\
-1.8\end{array}$ & $\begin{array}{l}21 \\
22 \\
22 \\
22 \cdot 5 \\
23 \\
23 \cdot 5 \\
23 \\
23\end{array}$ & $\begin{array}{l}762 \cdot 7 \\
762 \cdot 7 \\
762 \cdot 2 \\
762 \cdot 2 \\
762 \\
761 \cdot 2 \\
760 \cdot 5 \\
760 \cdot 4\end{array}$ \\
\hline \multicolumn{9}{|c|}{ Sulphuric Acid, $\mathrm{SO}_{4} \mathrm{H}_{2}$. } \\
\hline $\begin{array}{l}0 \dagger \\
0 \neq \\
0.0007611+ \\
0.008329 \ddagger \\
0.015875 \ddagger\end{array}$ & $\begin{array}{l}-4841(2) \\
44824(5) \\
44809 \\
\cdot 4455 \\
\cdot 4139\end{array}$ & $\begin{array}{l}9 \\
\mathbf{5} \\
6 \\
5 \\
7\end{array}$ & $\begin{array}{l}\cdot 4841-\cdot 4842 \\
\cdot 4824-\cdot 4825 \\
\cdot 4808-\cdot 4810 \\
\cdot 4455 \\
\cdot 4139\end{array}$ & $\begin{array}{r}10 \\
10 \\
10 \\
10 \\
9\end{array}$ & $\begin{array}{l}\cdots \\
\cdots \\
\cdots \\
\cdots\end{array}$ & $\begin{array}{l}-2 \\
-2 \\
-2 \\
-2 \\
-2\end{array}$ & $\begin{array}{l}18 \\
18 \\
18 \\
18 \\
18\end{array}$ & $\begin{array}{l}752 \cdot 3 \\
752 \cdot 3 \\
752 \cdot 3 \\
752 \cdot 3 \\
752 \cdot 3\end{array}$ \\
\hline $\begin{array}{l}0 * \\
0 \dagger \\
0+ \\
0.00456+ \\
0.00456+\end{array}$ & $\begin{array}{l}\cdot 4814 \\
\cdot 4829 \\
\cdot 4829(30) \\
\cdot 4609 \\
\cdot 4609\end{array}$ & $\begin{array}{r}10 \\
5 \\
7 \\
4 \\
11\end{array}$ & $\begin{array}{l}\cdot 4813-\cdot 4815 \\
\cdot 4829 \\
\cdot 4829-\cdot 4830 \\
\cdot 4606-\cdot 4609 \\
\cdot 4608-\cdot 4609\end{array}$ & $\begin{array}{r}8 \\
8 \\
7 \\
10 \\
10\end{array}$ & $\begin{array}{l}\cdots \\
\cdots \\
\cdots \\
\cdots\end{array}$ & $\begin{array}{l}-2 \\
-2 \\
-2 \\
-2 \\
-2\end{array}$ & $\begin{array}{l}17 \\
17 \\
17 \\
17 \\
17\end{array}$ & $\begin{array}{l}749 \cdot 2 \\
749 \cdot 5 \\
749 \cdot 5 \\
749 \cdot 5 \\
749 \cdot 5\end{array}$ \\
\hline $\begin{array}{l}0 \dagger \\
0.00456 \uparrow \\
0.00456 \dagger \\
0.008329\end{array}$ & $\begin{array}{l}\cdot 4842(3) \\
+4620(19) \\
+4620(19) \\
\cdot 4457(6)\end{array}$ & $\begin{array}{l}8 \\
8 \\
6 \\
7\end{array}$ & $\begin{array}{l}\cdot 4842-\cdot 4843 \\
\cdot 4619-\cdot 4620 \\
\cdot 4619-\cdot 4620 \\
\cdot 4456-\cdot 4457\end{array}$ & $\begin{array}{r}8 \\
12 \\
8 \\
9\end{array}$ & $\begin{array}{l}\cdots \\
\cdots \\
\cdots \\
\cdots\end{array}$ & $\begin{array}{c}-1.8 \text { bisto }-2 \\
-1.9 \\
-1.9 \\
-2\end{array}$ & $\begin{array}{l}19 \\
19 \\
19 \\
19\end{array}$ & $\begin{array}{l}752 \cdot 7 \\
752 \cdot 9 \\
753 \cdot 5 \\
754 \cdot 7\end{array}$ \\
\hline $\begin{array}{l}0 \dagger \\
0 \dagger \\
0.008367 \dagger \\
0.008367 \dagger \\
0.015912 \ddagger \\
0.03092 \ddagger \\
0.03092 \ddagger\end{array}$ & $\left|\begin{array}{l}\cdot 4849 \\
-4849(50) \\
-4466(7) \\
4465(6) \\
-4148 \\
-3539(40) \\
-3540(39)\end{array}\right|$ & $\begin{array}{r}5 \\
11 \\
6 \\
8 \\
9 \\
6 \\
10\end{array}$ & $\begin{array}{l}\cdot 4849 \\
\cdot 4849-\cdot 4850 \\
\cdot 4466-\cdot 4468 \\
\cdot 4465-\cdot 4466 \\
\cdot 4147-\cdot 4150 \\
\cdot 3539-\cdot 3540 \\
\cdot 3539-\cdot 3540\end{array}$ & $\begin{array}{r}8 \\
10 \\
10 \\
10 \\
10 \\
10 \\
10\end{array}$ & $\begin{array}{l}\cdots \\
\cdots \\
\cdots \\
\cdots \\
\cdots \\
\cdots\end{array}$ & $\begin{array}{c}-2 \\
-2 \\
-1.8 \text { bisto-2 } \\
-1.8 \\
-1.8 \\
-1.8 \\
-2\end{array}$ & $\begin{array}{l}18 \\
18 \\
18 \cdot 5 \\
19 \\
19 \\
19 \\
19\end{array}$ & $\begin{array}{l}755 \cdot 8 \\
755 \cdot 8 \\
755 \cdot 6 \\
755 \cdot 6 \\
755 \cdot 5 \\
755 \cdot 3 \\
755 \cdot 3\end{array}$ \\
\hline $\begin{array}{l}0 \dagger \\
0.04567 \ddagger \\
0.06740 \ddagger \\
0.09569 \ddagger\end{array}$ & $\begin{array}{l}4839(40) \\
\cdot 2951(2) \\
\cdot 2118(9) \\
\cdot 1038(9)\end{array}$ & $\begin{array}{r}9 \\
10 \\
8 \\
9\end{array}$ & $\begin{array}{l}\cdot 4830-\cdot 4830 \\
\cdot 2951-\cdot 2955 \\
\cdot 2116-\cdot 2121 \\
\cdot 1038-\cdot 1039\end{array}$ & $\begin{array}{r}10 \\
11 \\
8 \\
8\end{array}$ & $\begin{array}{l}\cdots \\
\cdots \\
\cdots \\
\cdots\end{array}$ & $\begin{array}{l}-1 \cdot 8 \\
-2 \\
-1 \cdot 8 \\
-1 \cdot 9\end{array}$ & $\begin{array}{l}18 \cdot 5 \\
18 \cdot 7 \\
19 \\
20\end{array}$ & $\begin{array}{l}753 \cdot 3 \\
753 \cdot 3 \\
753 \cdot 2 \\
753 \cdot 2\end{array}$ \\
\hline $\begin{array}{l}0 \dagger \\
0 \cdot 1436 \ddagger \\
0 \cdot 18645 \ddagger\end{array}$ & $\left|\begin{array}{l}6 \cdot 147 \\
5 \cdot 590 \\
5 \cdot 429(30)\end{array}\right|$ & $\begin{array}{c}(\mathrm{Sm} \\
7 \\
8\end{array}$ & $\begin{array}{l}\text { all thermomet } \\
5 \cdot 589-5 \cdot 591 \\
5 \cdot 428-5 \cdot 430\end{array}$ & $\begin{array}{l}8 \\
8\end{array}$ & $\begin{array}{l}\ldots \\
\ldots \\
\ldots\end{array}$ & $\begin{array}{l}-2 \\
-2 \\
-2\end{array}$ & $\begin{array}{l}18 \\
18 \\
18\end{array}$ & \\
\hline
\end{tabular}

* Ice-cap round the bulb of thermometer.

t The ice-cap is avoided in a manner described in Zeitschr. phys, Chemie, xv.

$\ddagger$ No ice-cap on the $\mathrm{Hg}$ bulb of the thermometer.

From these experimental data are deduced the following Tables (Tables VI. 1-3), 
In these Tables are given under $a_{1}^{\prime}$ the degrees of dissociation as deduced from the freezing-point, when the value of Van't Hoff's constant is taken to be $1.87 ; a_{2}$ gives the degrees of dissociation as determined by electric conductivity by a careful interpolation. The result is that the agreement between the values $a_{1}^{\prime}$ and $a_{2}$ is excellent. I think, therefore, that the latent heat of ice is more correctly estimated at 80 than at $79 \mathrm{cal}$. It appears that the degrees of dissociation deduced from the freezing-point under $a_{1}^{\prime}$ are somewhat smaller than those deduced from electric conductivity. Now the valies of $a, a_{1}^{\prime}$, and $a_{2}$ have been determined at various temperatures (from about $0^{\circ}$ and $18^{\circ}$ or $25^{\circ}$ ), and in view of the investigations of Kohlrausch and Ostwald (on acetic acid, \&c.), we have good ground for presuming that the degree of dissociation deduced from electric conductivity would be somewhat smaller for the same concentration at lower temperatures. I also think-being, till lately, singular in this opinion - that we may assume that in the solutions there are always present, in greater or lesser number, still higher undissociated and dissociated molecules which cause greater or lesser deviations from the strict agreement of the degrees of dissociation as deduced from the freezing-point and from electric conductivity. But the most probable reason is, that the absolute value of the graduated scale of the $\frac{1}{000} 0^{\circ}$ thermometer is, between 0.49 and $0 \cdot 36,1-2$ per cent. too small. From various causes 1 regard this as very probable. My further investigations will decide this question. In every case we ought, no doubt, in our calculations of the degrees of dissociation to use in all our given concentrations, or in concentrations measured by the scale 0.49 to 0.36 , the value 1.84 or 1.85 instead of the theoretical 1.87 , since we have practically found in the case of non-electrolytes under similar conditions in the more dilute solutions the value 1.85 or 1.84 . If we do so, the law of Arrhenins finds in the observations given above the most wonderful, unexpected confirmation. See in the table above, $a_{1}$ and $a_{2}$. In any case, look at the above results how we may, there is no doubt that the law of Arrhenius has found remarkable confirmation in the cases of the nonconductors cane-sugar, urea, and alcohol, and of the conductors potassium chloride, sulphuric acid, dichloracetic acid, trichloracetic acid, orthonitrobenzoic acid. 
Dr. M. Wildermann on the

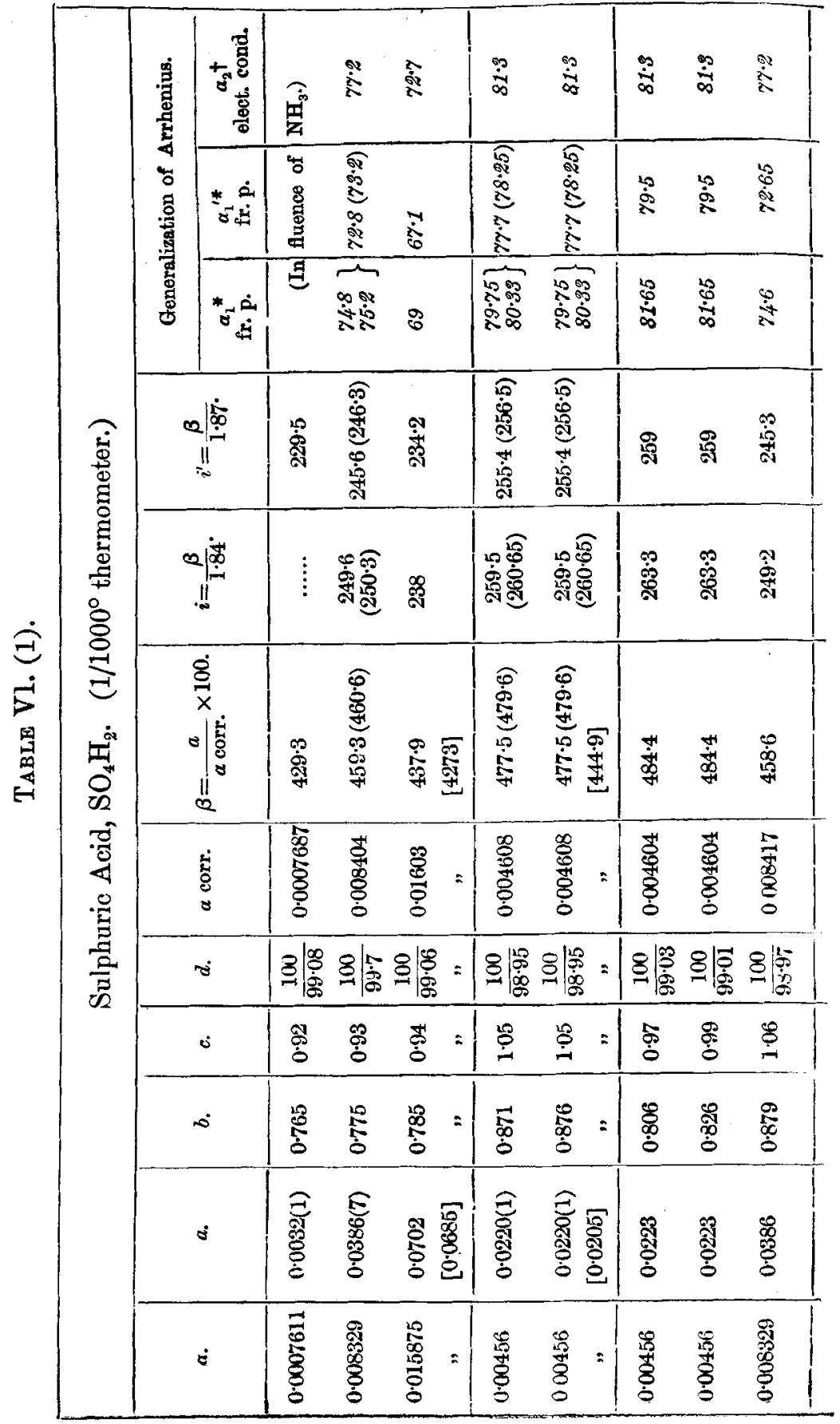




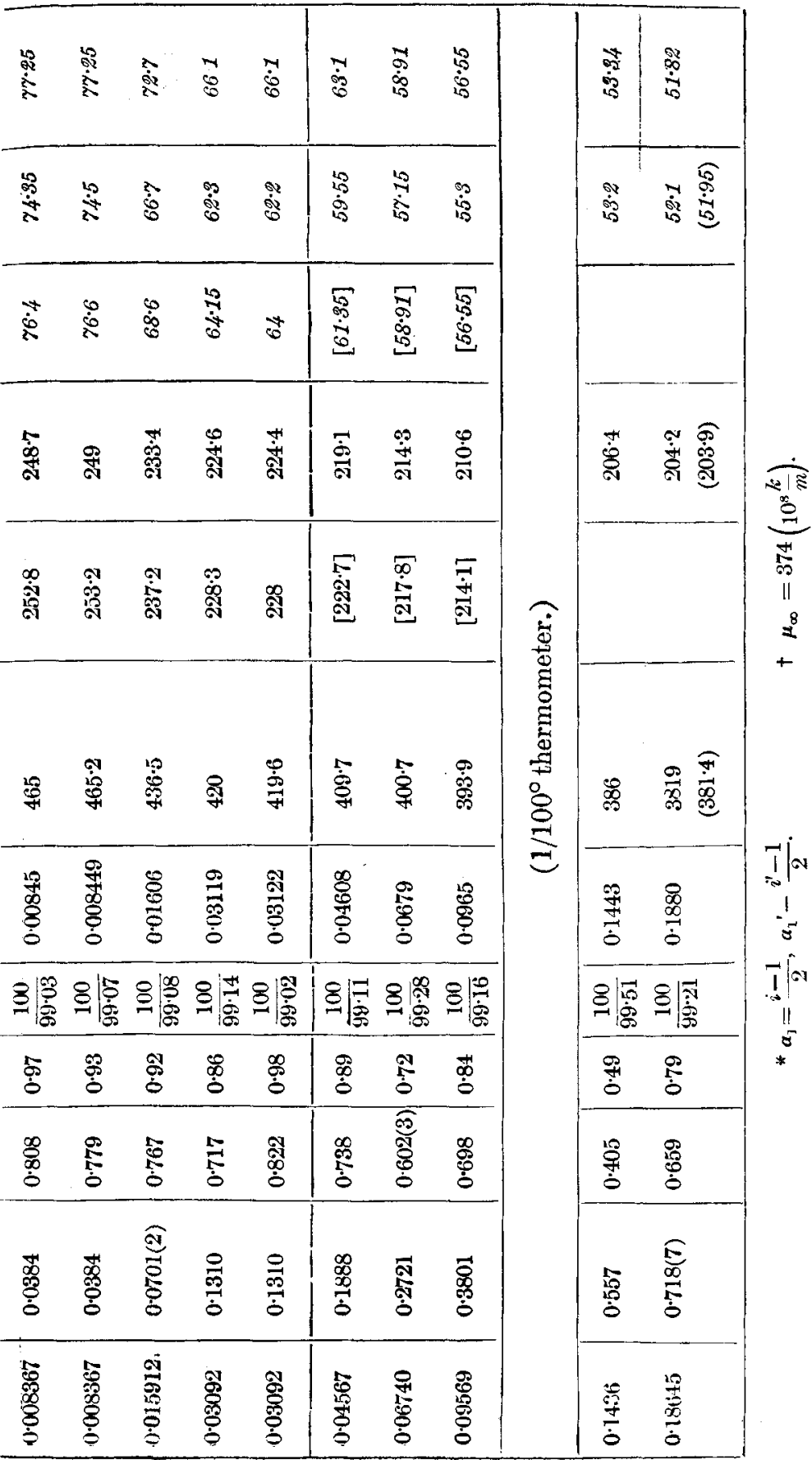




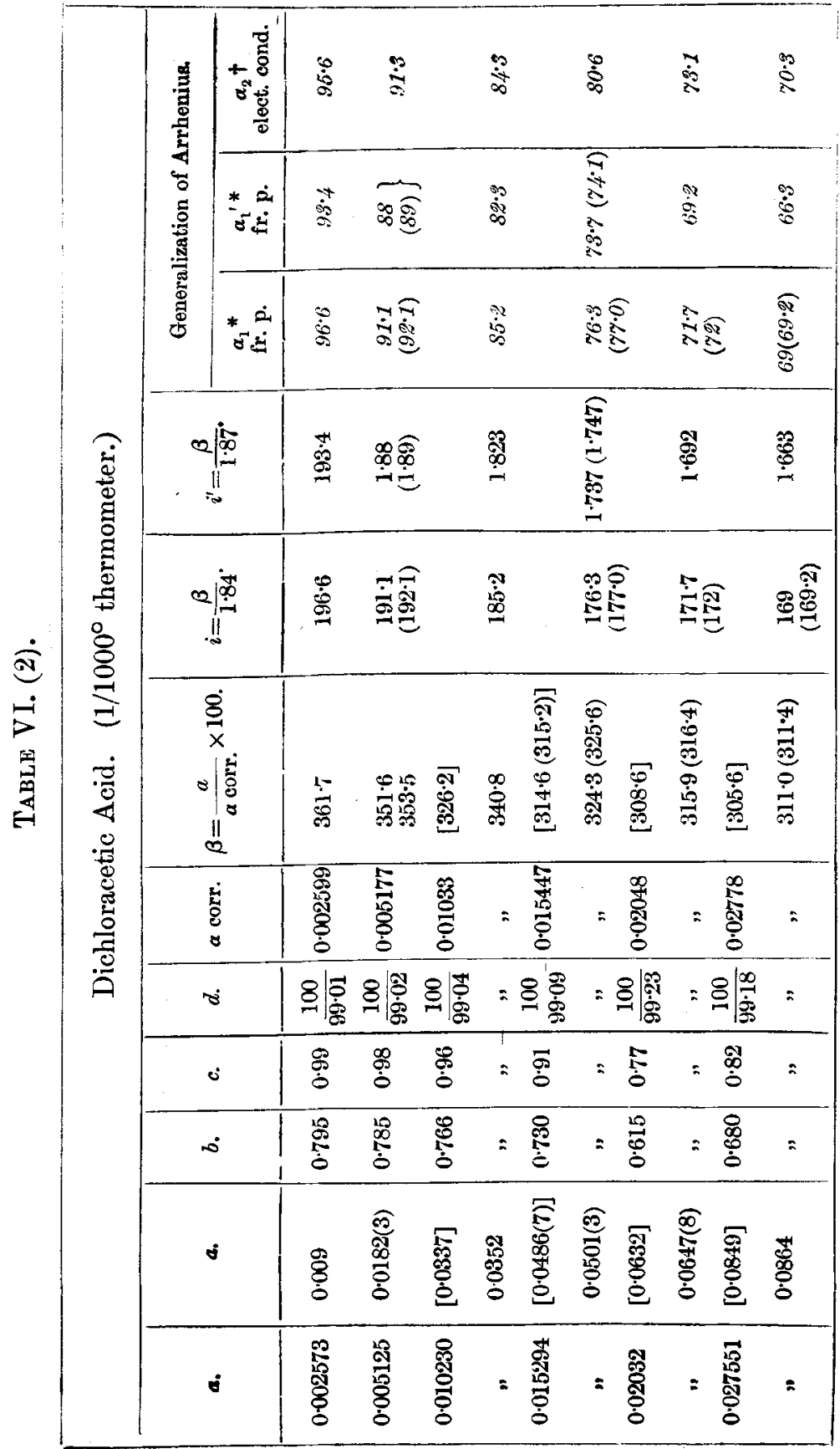


Proof of Arrhenius's Generalization.

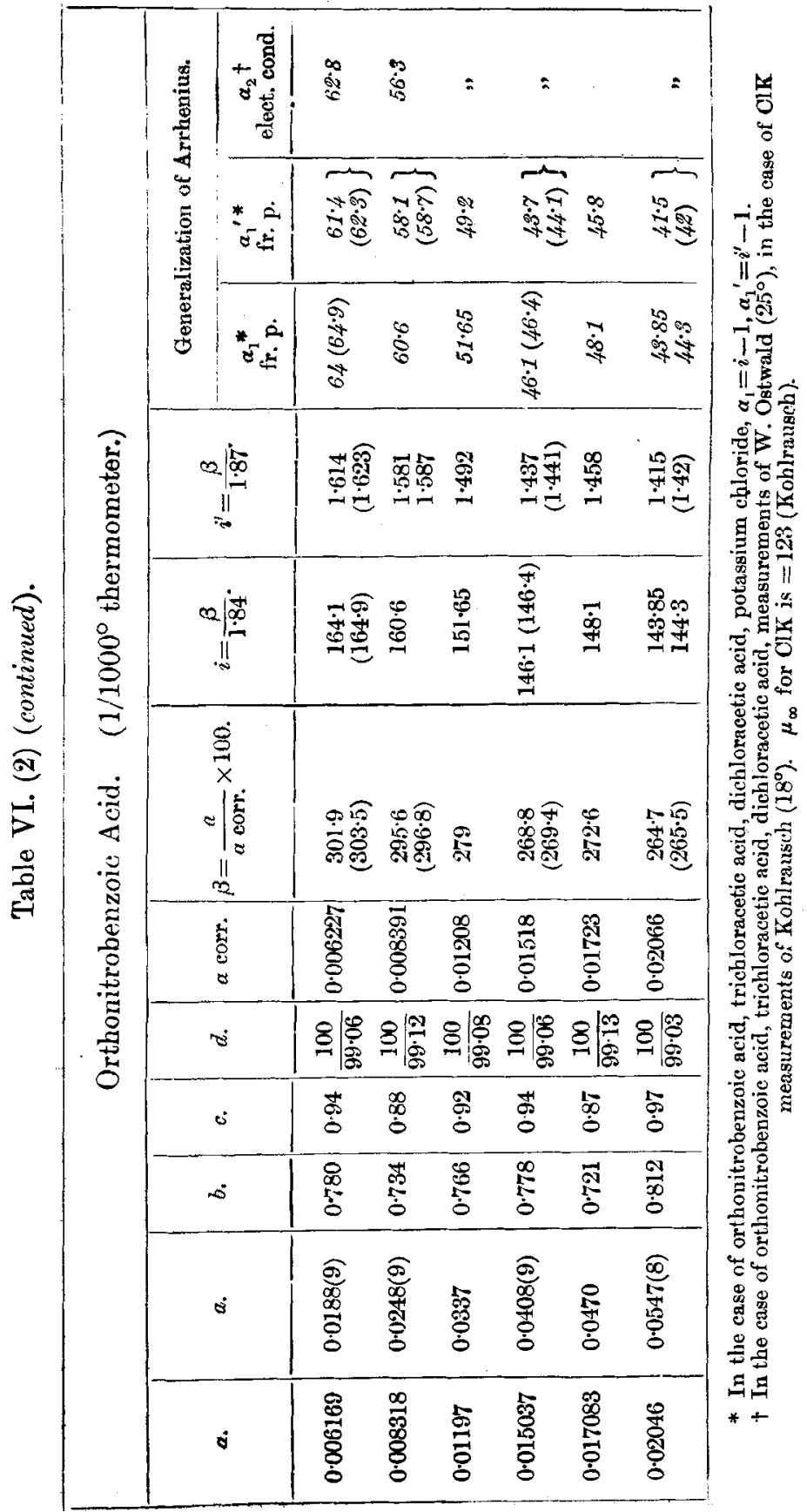




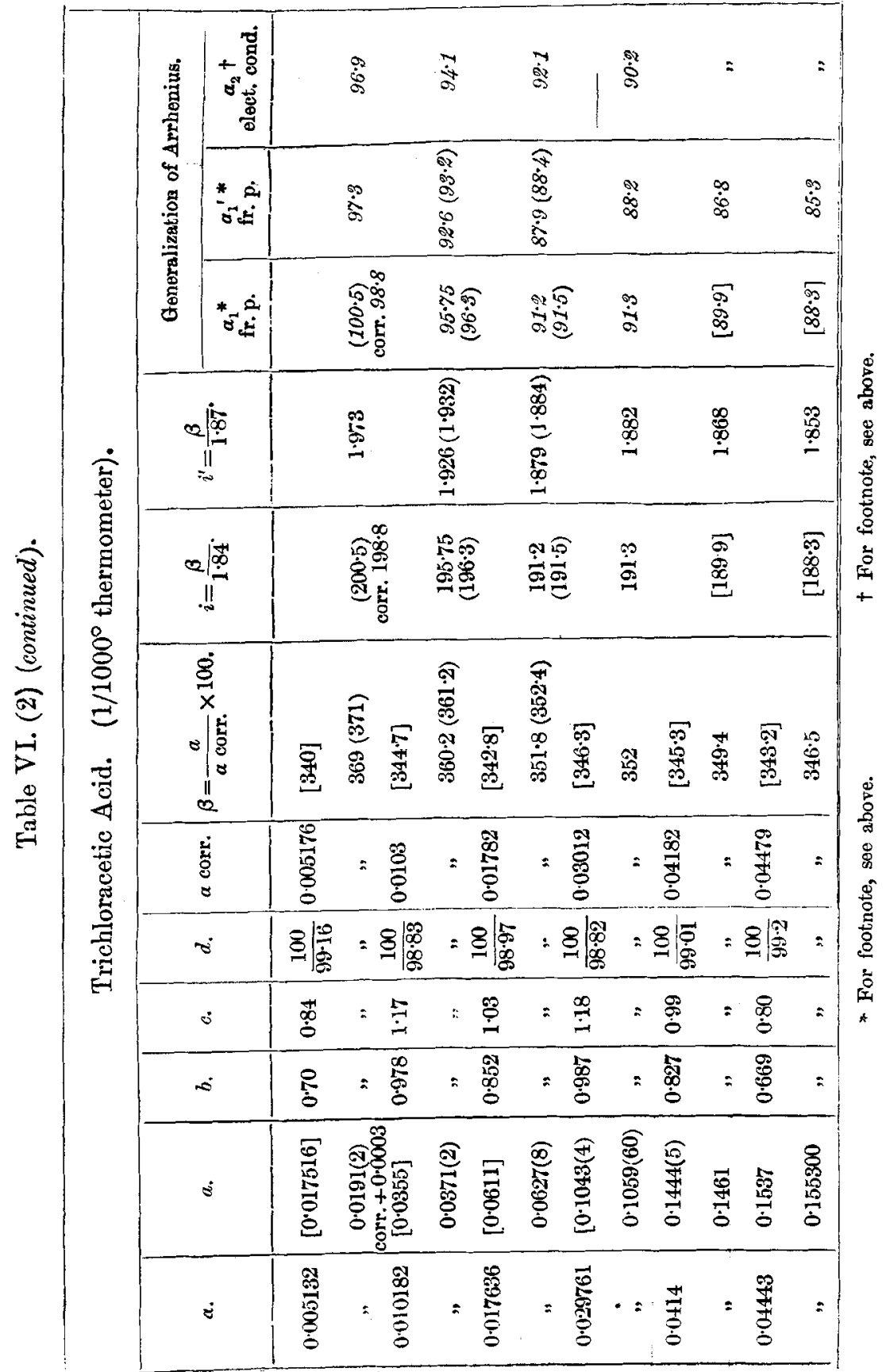


Proof of Arrhenius's Generalization.

141.

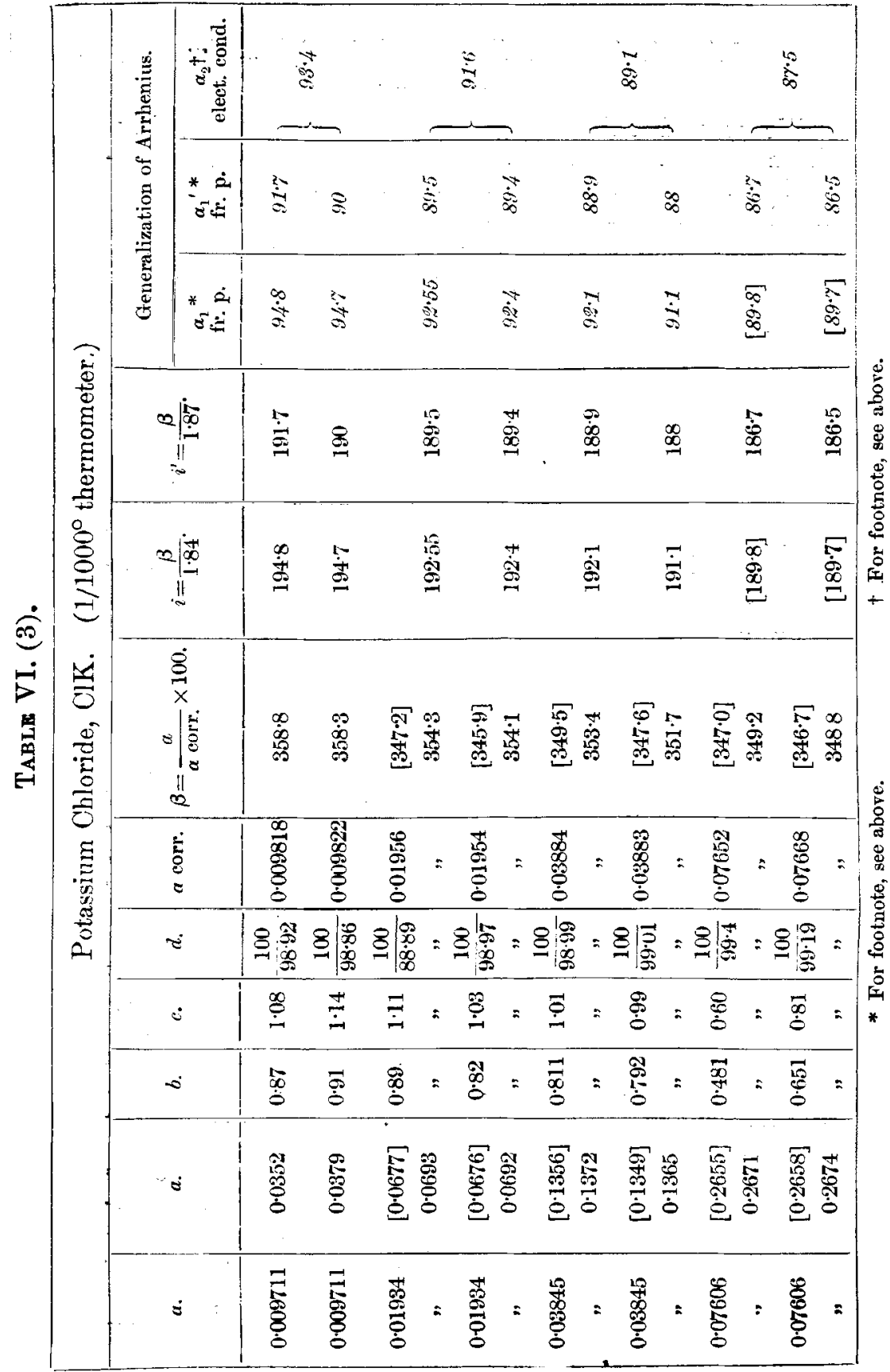




\section{The Law of Dilution as deduced from the Freezing-Point.}

We proceed to illustrate one of the most important, if not the most important, of the foundations of the theory of dissociation, namely, Ostwald's law of dilution based upon the freezing-point. (Planck's name also should be mentioned here.) It was notably Ostwald who first showed the relation between the numbers of dissociated and undissociated molecules to depend upon the action of mass, and who took the pains to verify the same experimentally in the case of two hundred acids by means of their electric conductivity. From the above-mentioned generalization of Arrhenius it follows that the law of dilution ought also to be deducible from the freezing-point, since the freezing-point as well as the electric conductivity enables one to know the degree of dissociation, and it may be at the same time interesting, inasmuch as we have not bere to do with velocity of ions or with the theory of the electric conductivity. On the other hand, from the intimate connexion which exists between Van't Hoff's laws and the dissociation theory, it follows that the law of dilution must find its experimental confirmation in dilute solutions. This has not been possible before now, because the constant deduced from the law of dilution is greatly affected by the experimental error, and the freezing methods were till now far from being sufficiently exact for this purpose. But we have now made a sufficient advance in the freezing methods to be able to undertake this proof under favourable circumstances. Here we have to take into account two conditions : first, the degree of dissociation must not be small, especially because, in consequence of the nature of the calculation, the experimental error affects not the whole value observed, but only that part of it which gives the degree of dissociation; secondly, the degree of dissociation must very considerably change with the degree of dilution, or else the influence of dilution is difficult to ascertain. The law of dilution can therefore only be proved in the case of a few substances which fulfil these conditions. Dichloracetic acid and orthonitrobenzoic acid are suitable for this purpose.

Below are given the constants calculated according to the law of dilution in the cases of dichloracetic acid and orthonitrobenzoic acid. In the last Table are given under " $a$ corrected" the concentrations of the solutions, and under $\Delta$ the degree of dissociation, when $t=1 \cdot 87$. The constant $\mathrm{K}$ given by the law of dilution appears indubitably, but is smaller 
Dilution in very Dilute Solutions.

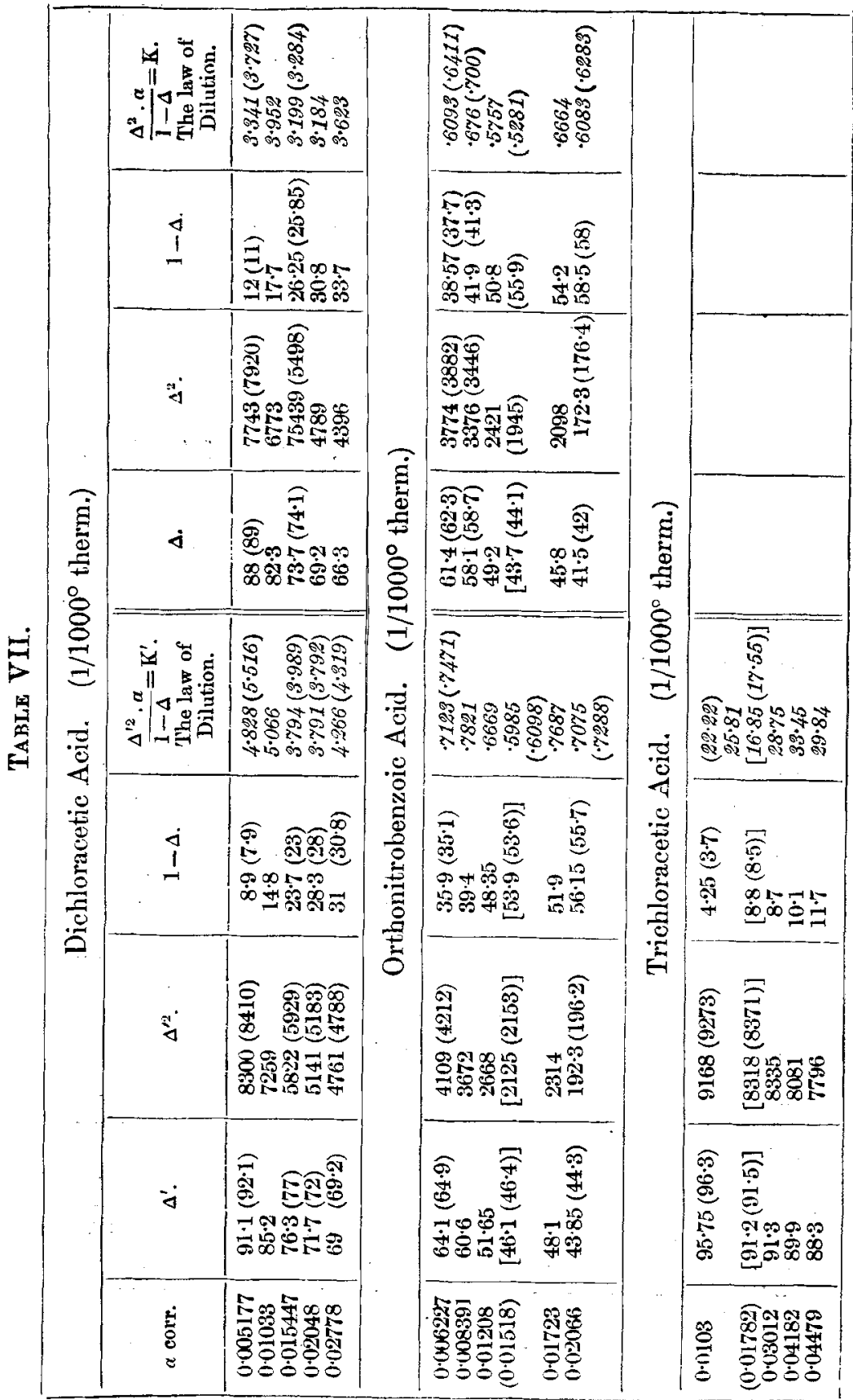


than that deduced from electric conductivity ( $25^{\circ}$ Ostwald) Much better is the agreement between the constant from treezing-point and the constant from electric conductivity, if the practically found $t=1.84$ is used; the constant is well obtained then also in the case of trichloracetic acid. See $\Delta^{\prime}$ and $\mathrm{K}^{\prime}$ in Table VII.

I may be permitted to express my heartiest thanks to the authorities of Christ Church and to Mr. A. G. Vernon Harcourt for kindly placing the resources of their laboratory at my disposal.

Christ Church, Oxford.

VII. Notices respecting Nev Books.

Annals of British Geology, 1893. By J. F. BuAKe, M.A., F.G.S. 8 vo., xxiv and 365 pages, with 90 illustrations, February 1895. Dulau \& Co., London.

THIS digest of Books and Papers published during the year (1893), with an Introductory Review, is a welcome continuation of three former volumes, already noticed in the "Philosophical Magazine.' The subjects taken in order from page 1 to page 301 are :- 1. General Geology ; 2. Stratigraphical Geology ; 3. Palæontology ; 4. Palæobotany; 5. Mineralogy; 6. Petrology; 7. Economical products; 8. Maps and Sections relating to Eingland and Scotland. Notices of notes and memoirs on Foreign Greology, published in Britain, taken in much the same order as the above, occupy pages 302-353. Three good Indexes are found at pages $355-365$.

The aim of this work is to provide annually for students of Geology a condensed account of all that has been done in the science so far as the British Islands are concerned. For this purpose the various papers and other publications are classified under larger and smaller subdivisions, so that the whole work is a kind of subject-index.

The several papers are either merely recorded, or more or less fully abstracted. The "Introductory Review" aims at giving a succinct account of the general progress in Geological science, and treatment of disputed questions, during the year concerned, based on the information afforded by the said publications. Where desirable and convenient, especially with new species of fossils, figures (copied by "process") are given in the text. In the abstracts of the papers the ideas advanced or supported by the several authors are represented from their own points of view ; in the "Introductory Review" the reviewer (he objects to be regarded as a "compiler" of this most careful and laborious work) writes critically on his own responsibility.

The number of publications dealt with each year has varied 